AperTO - Archivio Istituzionale Open Access dell'Università di Torino

\title{
Tuning TiO2 nanoparticle morphology in graphene-TiO2 hybrids by graphene surface modification
}

\section{This is the author's manuscript}

Original Citation:

Availability:

This version is available http://hdl.handle.net/2318/158131

since 2016-06-28T15:54:07Z

Published version:

DOI:10.1039/c4nr01322k

Terms of use:

Open Access

Anyone can freely access the full text of works made available as "Open Access". Works made available under a Creative Commons license can be used according to the terms and conditions of said license. Use of all other works requires consent of the right holder (author or publisher) if not exempted from copyright protection by the applicable law. 


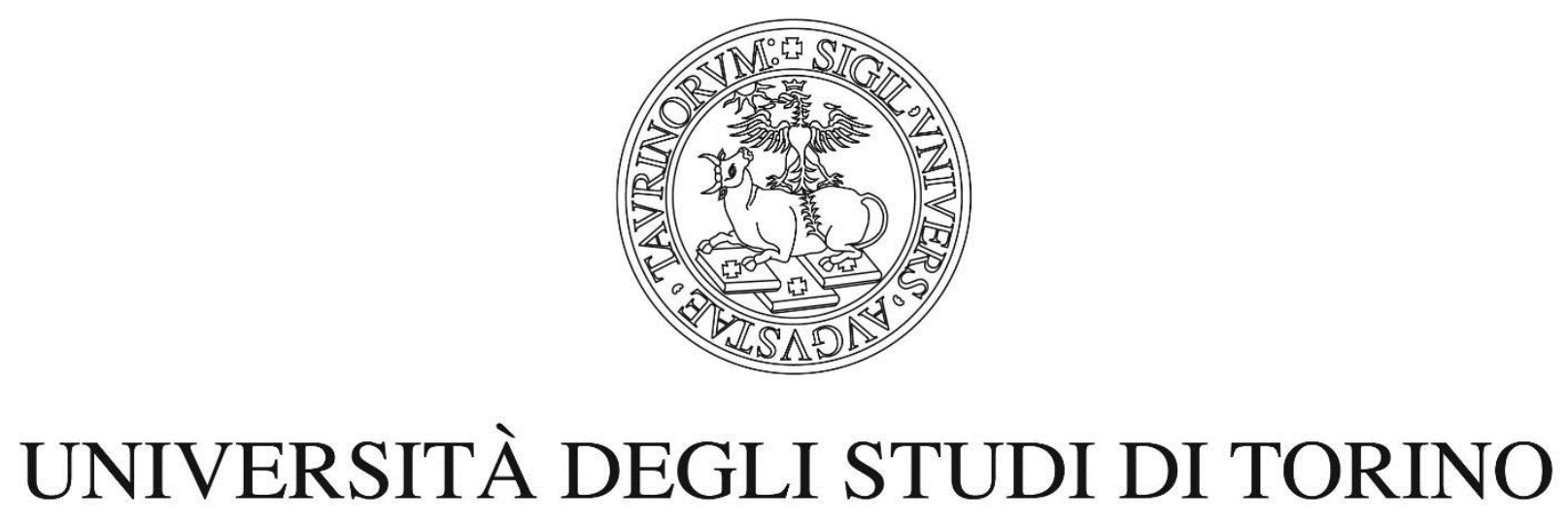

This is an author version of the contribution published on:

Questa è la versione dell'autore dell'opera:

“Tuning $\mathrm{TiO}_{2}$ nanoparticle morphology in graphene-TiO $\mathrm{T}_{2}$ hybrids by graphene surface modification",

F. Sordello, G. Zeb , K. Hu, P. Calza, C. Minero, T. Szkopek and M. Cerruti

Nanoscale 2014, 6 (12), $6710-6719$.

The definitive version is available at:

$L a$ versione definitiva è disponibile alla $U R L$ :

http://pubs.rsc.org/en/content/articlehtml/2014/nr/c4nr01322k 



\title{
Tuning $\mathrm{TiO}_{2}$ nanoparticle morphology in graphene- $\mathrm{TiO}_{2}$ hybrids by graphene surface modification
}

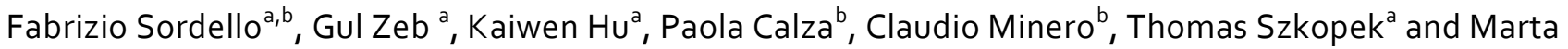 \\ Cerruti $^{\mathrm{a}}$
}

\begin{abstract}
We report the hydrothermal synthesis of graphene (GNP)- $\mathrm{TiO}_{2}$ nanoparticle (NP) hybrids using $\mathrm{COOH}$ and $\mathrm{NH}_{2}$ functionalized GNP as shape controller. Anatase was the only $\mathrm{TiO}_{2}$ crystalline phase nucleated on the functionalized GNP, whereas traces of rutile were detected on unfunctionalized GNP. X-Ray Photoelectron spectroscopy (XPS) showed C-Ti bonds on all hybrids, thus confirming heterogeneous nucleation. GNP functionalization induced the nucleation of $\mathrm{TiO}_{2} \mathrm{NPs}$ with specific shape and crystalline facets exposed. COOH functionalization directed the synthesis of anatase truncated bipyramids, bonded to graphene sheets via the $\{101\}$ facets, while $\mathrm{NH}_{2}$ functionalization induced the formation of belted truncated bipyramids, bonded to graphene via the \{100\} facets. Belted truncated bipyramids formed on unfuctionalized GNP too, however the NPs were more irregular and rounded. These effects were ascribed to pH variations in the proximity of the functionalized GNP sheets, due to the high density of $\mathrm{COOH}$ or $\mathrm{NH}_{2}$ groups. Because of the different reactivity of anatase $\{100\}$ and $\{101\}$ crystalline facets, we hypothesize that the hybrid materials will behave differently as photocatalysts, and that the $\mathrm{COOH}-\mathrm{GNP}-\mathrm{TiO}_{2}$ hybrids will be better photocatalysts for water splitting and $\mathrm{H}_{2}$ production.
\end{abstract}

\section{Introduction}

Titania nanoparticles ( $\mathrm{TiO}_{2}$ NPs) have been used in a wide variety of applications including pollutant abatement, ${ }^{1,} 2$ photovoltaics, ${ }^{3}$ water photosplitting, ${ }^{4-6}$ and lithium ion batteries. $^{7-9}$ In most of these applications, not only the phase and size of $\mathrm{TiO}_{2}$ NPs, but also their shape and the extent to which different facets are developed determine the NP activity. ${ }^{10-12}$ For example, while the $\{101\}$ facets are the most thermodynamically stable in $\mathrm{TiO}_{2}$ anatase, the $\{001\}$ facets are often preferred due to their higher reactivity ${ }^{13}$ and higher oxidating ability. ${ }^{14,15}$

Anatase crystals found in nature have a tetragonal bipyramidal shape, often truncated, which exposes eight equivalent $\{101\}$ facets and two equivalent $\{001\}$ facets (Fig. 1a). ${ }^{16}$ This corresponds to the equilibrium morphology based on Wulff construction. ${ }^{17}$ This morphology can be changed by synthesizing anatase NPs in the presence of specific shape controllers. ${ }^{12,18-20}$ A first breakthrough was achieved by Lu et al, ${ }^{21,22}$ who synthesized $\mathrm{TiO}_{2}$ NPs with a very high percentage of exposed $\{001\}$ facets using hydrofluoric acid; such particles showed excellent photocatalytic activity.

Most of the shape controllers used in $\mathrm{TiO}_{2}$ synthesis have amino and carboxylic groups in their structure, since these functionalities are known to interact with $\mathrm{TiO}_{2}$ facets. ${ }^{18}$ Specifically, amino groups can adsorb on and stabilize facets that are parallel to the c-axis such as the $\{101\}$ facets, while carboxylates seem to adsorb prevalently on $\{001\}$ facets. ${ }^{18-20,23}$ This implies that carboxylic (acetic, oleic, stearic) acids favor the growth of cubic particles, with $\{100\}$ and $\{001\}$ facets exposed, ${ }^{18}$ whereas amino acids and aliphatic amines promote the growth of $\{101\}$ and $\{100\}$ facets. ${ }^{18-20,23}$ For example, Dai et $\mathrm{al}^{20}$ produced $\sim 40 \mathrm{~nm}$ long $\mathrm{TiO}_{2}$ NPs in the shape of truncated tetragonal bipyramids exposing $\{001\}$ and $\{101\}$ facets using acetic acid as shape controller.

Particle morphology can also be controlled with $\mathrm{pH}$. At low $\mathrm{pH}$, predominantly truncated bipyramids are found, ${ }^{24-26}$ similar to the most thermodynamically stable structure. Indeed, at acidic $\mathrm{pH}$ the minimum energy surfaces are the hydrated $\{101\}$ (surface energy $1.03 \mathrm{~J} \mathrm{~m}^{-2}$ ), \{100\} (1.113 $\mathrm{J} \mathrm{m}^{-2}$ ) and $\{001\}$ $\left(1.55 \mathrm{~J} \mathrm{~m}^{-2}\right.$ ) surfaces. ${ }^{16}$ At basic $\mathrm{pH}$, the order of stability of the exposed surfaces is reversed, and the $\{100\}$ facet becomes the most stable (surface energy $1.53 \mathrm{~J} \mathrm{~m}^{-2}$ ) with respect to the $\{101\}\left(2.07 \mathrm{~J} \mathrm{~m}^{-2}\right)$, and the $\{001\}\left(2.55 \mathrm{~J} \mathrm{~m}^{-2}\right)$ facets. ${ }^{16}$ In this case the equilibrium shape is the truncated belted bipyramid with an important development of $\{100\}$ surfaces (Fig. 1b). ${ }^{24,27}$

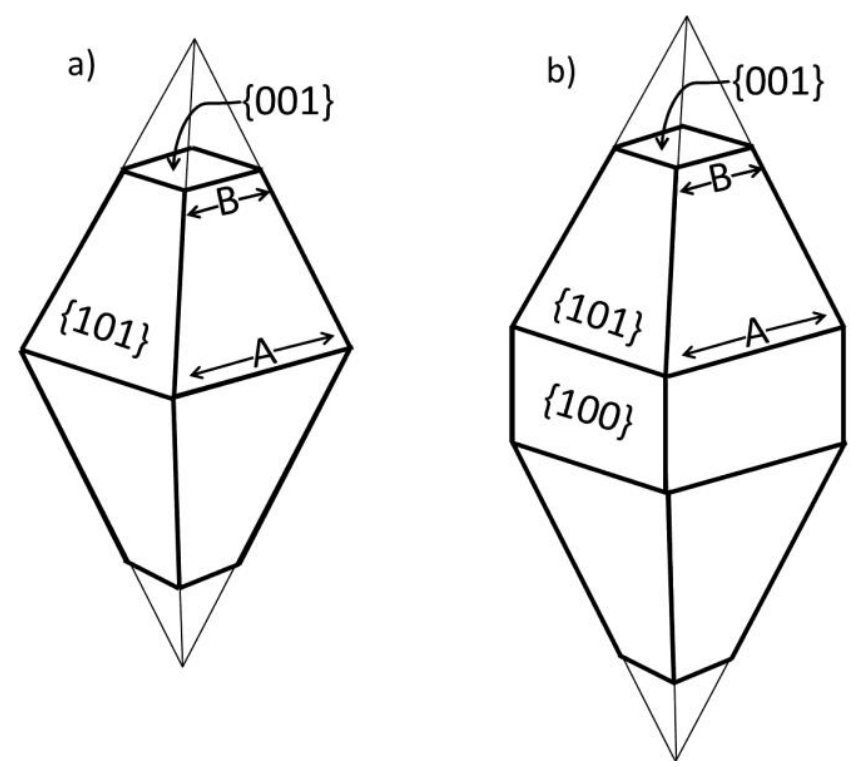

Figure 1: a) Anatase tetragonal bipyramid with eight equivalent $\{101\}$ surfaces; the truncation gives rise to two equivalent $\{001\}$ facets; b) Anatase tetragonal belted bipyramid with eight equivalent $\{101\}$ surfaces, four equivalent $\{100\}$ facets and, when truncated, two equivalent $\{001\}$ surfaces. In both a) and b) the degree of truncation is defined as $B A^{-1}$ with $0<B<A$

Here we report for the first time that $\mathrm{TiO}_{2} \mathrm{NP}$ shape can be controlled by functional groups that are immobilized on a 
substrate rather than free in solution. Specifically, we show that functionalized graphene nanoplatelets (GNP) can be used as nucleation sites for $\mathrm{TiO}_{2} \mathrm{NPs}$, and that the presence of amino or carboxylate groups on GNP influences $\mathrm{TiO}_{2}$ morphology. $\mathrm{GNP} / \mathrm{TiO}_{2}$ hybrids have recently attracted much interest due to their applications in photocatalysis ${ }^{28-32}$ and other fields. ${ }^{33,} 34$ Williams et $\mathrm{al}^{35}$ first synthesized $\mathrm{GNP}^{-\mathrm{TiO}_{2}}$ hybrids by simply irradiating a solution containing $\mathrm{TiO}_{2}$ NPs and graphene oxide (GO). More recent examples of hybrid materials made by mixing $\mathrm{TiO}_{2}$ and GNP include the addition of surfactants or polymers in the system. ${ }^{36-38}$

In-situ nucleation of $\mathrm{TiO}_{2} \mathrm{NPs}$ on GO (reduced to GNP during the synthesis) was recently shown by Sun et al, ${ }^{30}$ who produced a hybrid including $\mathrm{TiO}_{2}$ "nanosheets" exposing mostly $\{001\}$ facets with the addition of HF during the synthesis. Other work on the one-pot synthesis of $\mathrm{GNP}_{-} \mathrm{TiO}_{2}$ hybrids does not show evidence of $\mathrm{TiO}_{2}$ shape control, ${ }^{39-44}$ and, when achieved, GNP does not play any significant role in shape control. $^{45-47}$

In this work, we bind both amino and carboxylate functions on GNP, and we show that these groups can change the morphology of $\mathrm{TiO}_{2}$ NPs grown during hydrothermal synthesis. The results obtained are different from what observed when shape controllers containing carboxylates and amino groups are used in solution; we hypothesize that this is due to a change in local $\mathrm{pH}$ rather than facet stabilization by molecular adsorption. The resulting materials include the first $\mathrm{GNP}_{-} \mathrm{TiO}_{2}$ hybrids in which $\mathrm{TiO}_{2}$ NPs preferentially show facets other than $\{001\}$.

\section{Materials and methods}

\section{Graphene nanopowder functionalization}

Graphene nanopowder (GNP, Graphene Supermarket, $3 \mathrm{~nm}$ flakes, Grade AO1, lateral size $10 \mu \mathrm{m}$ ) was modified with carboxylic groups using diazonium chemistry. ${ }^{48,49}$ To prepare this sample, denoted $\mathrm{COOH}-\mathrm{GNP}$, the GNP powder was added to a solution containing $0.05 \mathrm{M}$ 4-aminophenylacetic acid, 0.5 $\mathrm{M} \mathrm{HCl}$ and $0.05 \mathrm{M}$ sodium nitrite. All chemicals were purchased from Sigma Aldrich and used without further purification. The reaction was carried out for ten minutes; then COOH-GNP was filtered (Whatman cellulose acetate filter with $3.0 \mu \mathrm{m}$ pores) and washed several times with deionized
(DI) water and isopropyl alcohol, and left to dry overnight at $323 \mathrm{~K}$

To prepare $\mathrm{NH}_{2}-\mathrm{GNP}$, dried $\mathrm{COOH}-\mathrm{GNP}$ was chlorinated under reflux for $24 \mathrm{~h}$ with $\mathrm{SOCl}_{2}$ at $343 \mathrm{~K}$. After the evaporation of any remaining $\mathrm{SOCl}_{2}$, ethylenediamine was introduced in the reaction environment and $\mathrm{NH}_{2}-\mathrm{GNP}$ was obtained after refluxing for $24 \mathrm{~h}$ at $389 \mathrm{~K}$. The mixture was then cooled to room temperature, filtered, washed with DI water and isopropyl alcohol, and dried at $323 \mathrm{~K}$ overnight as for COOH-GNP samples.

\section{$\mathrm{TiO}_{2}$-graphene synthesis}

$\mathrm{TiO}_{2}$ - graphene composites (referred to as $\mathrm{GNP}-\mathrm{TiO}_{2}$ ) were produced via hydrothermal synthesis starting from $\mathrm{Ti}-$ triethanolamine 1:2 complex (Ti-TEOA) and GNP, COOHGNP and $\mathrm{NH}_{2}-\mathrm{GNP}^{19}$ Briefly, $50.0 \mathrm{mmol}$ of TIP were added drop wise to $100 \mathrm{mmol}$ of TEOA and then brought to $100 \mathrm{~mL}$ with DI water to give a Ti-TEOA complex solution 0.5 M. 8.00 $\mathrm{mL}$ of this solution and $10.0 \mathrm{mg}$ of GNP were added to 16.0 $\mathrm{mL}$ of DI water; the $\mathrm{pH}$ was measured and adjusted to a value between 9.5 and 10. The mixture was then brought to $40.0 \mathrm{~mL}$ with DI water, and the $\mathrm{pH}$ measured again and, if necessary, adjusted to between 9.5 and $10 . \mathrm{TiO}_{2}$ nucleation occurred while heating the reaction vessel at $383 \mathrm{~K}$ for $24 \mathrm{~h}$ first, and then at $418 \mathrm{~K}$ for $72 \mathrm{~h}$.

\section{Material characterization}

XPS. X-ray Photoelectron Spectroscopy (XPS) was carried out on a monochromatic X-ray photoelectron spectrometer K Alpha (Thermo Scientific). The instrument was equipped with an $\mathrm{Al} \mathrm{K} \alpha \mathrm{X}$-ray source (1486.6 eV, $0.834 \mathrm{~nm})$, a microfocused monochromator, and an ultrahigh vacuum chamber $\left(10^{-9}\right.$ torr).Survey scans (five points for each sample) and high resolution scans (three points for each sample) were collected with energy steps of 1 and $0.1 \mathrm{eV}$, respectively using an $\mathrm{X}$-ray beam spot $400 \mu \mathrm{m}$ wide. The spectral energies were calibrated by setting the binding energy (BE) of the $\mathrm{C} 1 \mathrm{~s}$ component corresponding to $\mathrm{C}-\mathrm{C}$ bonds to $284.4 \mathrm{eV}$.

RAMAN SPECTROSCOPY. Raman spectra were taken with a Bruker Senterra Raman Microscope using a $785 \mathrm{~nm}$ laser through a 40x objective. For each sample at least eight points were analyzed. 
a)<smiles>Nc1ccc(CC(=O)O[N+](=O)[O-])cc1</smiles>

b)<smiles>[N+]#[N+]c1ccc(CC(=O)O)cc1</smiles><smiles>[N+]#[N+]c1ccc(CC(=O)O)cc1</smiles>

c)

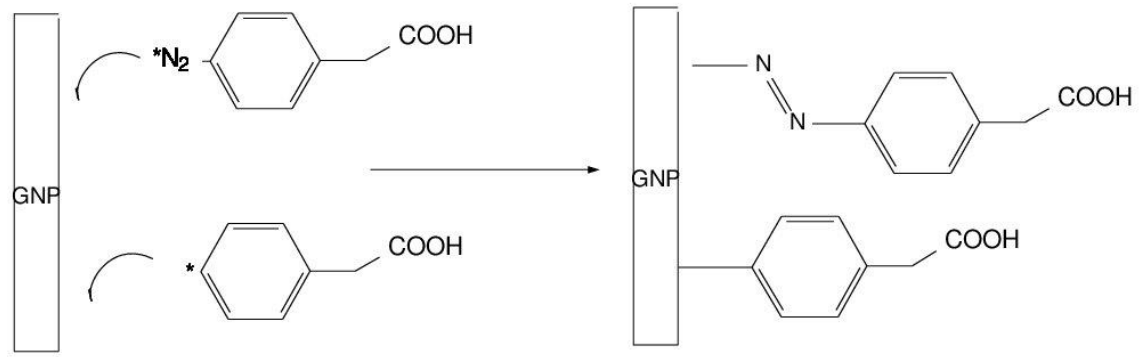

d)
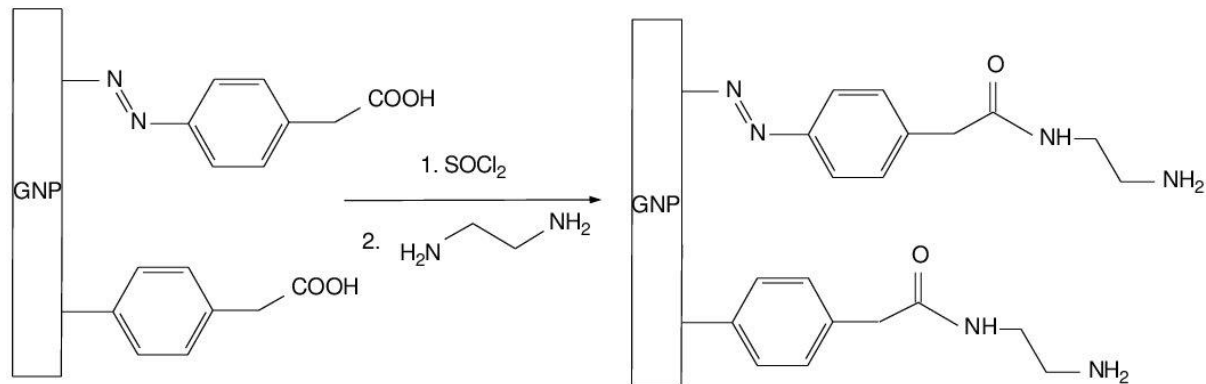

a) diazonium cation formation, b) diazonium reduction by GNP, c) radical addition and $\mathrm{COOH}-\mathrm{GNP}$ synthesis, d) $\mathrm{NH}_{2}$-GNP synthesis : $\mathrm{COOH}-\mathrm{GNP}$ is reacted with $\mathrm{SOCl}_{2}$ to activate the $\mathrm{COOH}$ groups and the subsequent reaction with ethylenediamine yields the $\mathrm{NH}_{2}$ functionalized GNP

TGA. Thermogravimetric analysis (TGA) was performed using a Q500 instrument from TA instruments. Analyses were performed in air, with a heating rate of $20 \mathrm{~K} \mathrm{~min}^{-1}$, and Pt pans were used for sample holders.

TEM. Transmission electron microscopy (TEM) images were taken on a Philips CM200 instrument operating at up to $200 \mathrm{kV}$, with line resolution of $0.14 \mathrm{~nm}$ and point resolution of $0.19 \mathrm{~nm}$.

\section{Results}

\section{Functionalized Graphene Nanopowders}

Our first goal was to produce functional GNP terminated with either $\mathrm{COOH}$ or $\mathrm{NH}_{2}$ groups, to use as templates for the synthesis of $\mathrm{TiO}_{2}$. Peng et al recently showed that it is possible to modify graphene with carboxylic groups using diazonium chemistry and 4-aminobenzoic acid. ${ }^{49}$ We used 4aminophenylacetic acid on the basis that this molecule would be a better binder for growing $\mathrm{TiO}_{2}$ particles due to the conformational freedom given by the methylenic spacer. A schematic of the diazonium reaction used to introduce $\mathrm{COOH}$ groups and the following amination step is shown in Scheme 1. Briefly, diazonium cations are produced at acidic $\mathrm{pH}$ in the presence of $\mathrm{NaNO}_{2}$ (Scheme 1a). GNP can reduce the diazonium cation to two different radicals (Scheme 1b), which are responsible for the GNP functionalization (Scheme 1c). ${ }^{50-53}$ To synthesize $\mathrm{NH}_{2}$-GNP, carboxylic groups are activated with $\mathrm{SOCl}_{2}$, and converted into amides by reaction with ethylenediamine, leaving an unreacted $\mathrm{NH}_{2}$ group at the end of the functional layer (Scheme 1d). ${ }^{54}$

The $\mathrm{C}, \mathrm{O}$ and $\mathrm{N}$ content in pristine and functionalized GNPs as measured by XPS are reported in Table 1. COOH-GNP shows an increase in $\mathrm{O}$, thus confirming the formation of extra carboxylate groups; a minor amount of $\mathrm{N}$ is present on this sample too, due to the formation of azo groups during the functionalization (Scheme 1c). A significant amount of $\mathrm{N}$ is measured on $\mathrm{NH}_{2}-\mathrm{GNP}$, thus confirming the introduction of 
Table 1: Carbon, oxygen and nitrogen content in the samples studied in the present work determined by XPS. Uncertainty has been estimated as twice the standard deviation.

\begin{tabular}{|c|c|c|c|}
\hline Sample 1 & $\mathrm{C} \%$ at & $\mathrm{O} \%$ at & $\mathrm{N} \%$ at \\
\hline GNP & $99.2 \pm 0.2$ & $0.8 \pm 0.2$ & n.d. \\
\hline COOH-GNP & $97.1 \pm 0.5$ & $2.2 \pm 0.2$ & $0.7 \pm 0.4$ \\
\hline $\mathrm{NH}_{2}-\mathrm{GNP}$ & $85 \pm 1$ & $5.6 \pm 0.5$ & $7.4 \pm 0.8$ \\
\hline
\end{tabular}
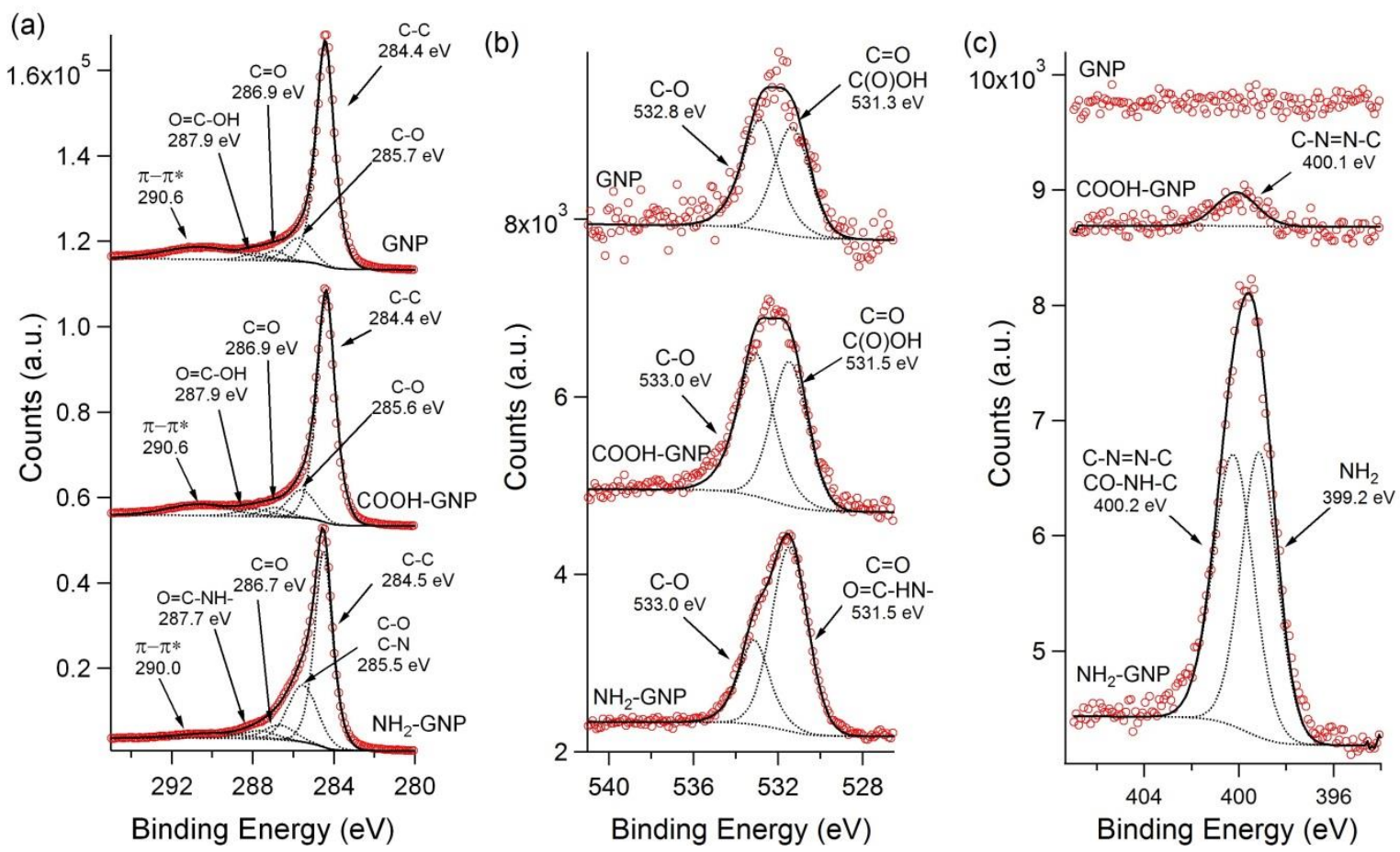

Figure 2: High resolution XPS spectra for GNP, $\mathrm{NH}_{2}-\mathrm{GNP}$ and $\mathrm{COOH}-\mathrm{GNP}$ samples relative to $\mathrm{C} 1 \mathrm{~s}(\mathrm{a}), \mathrm{O}$ 1s (b) and $\mathrm{N}$ 1s (c)
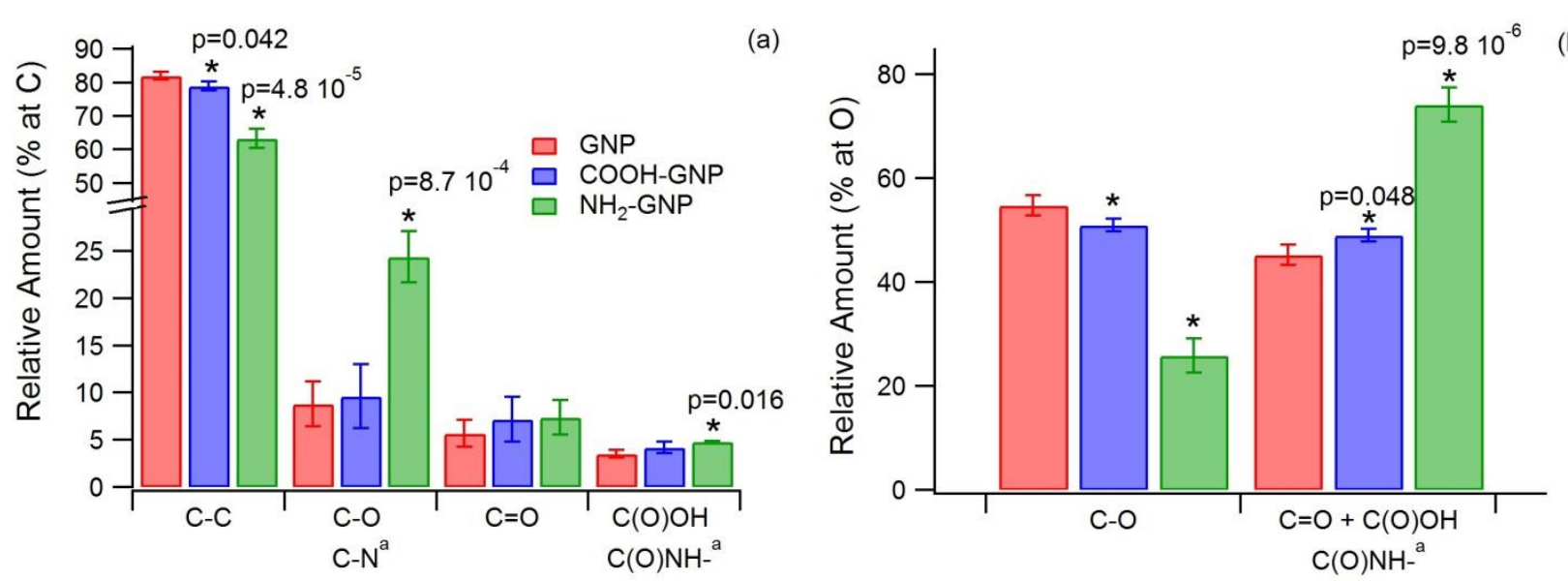

Figure 3: Relative amounts of the $\mathrm{C}(\mathrm{a})$ and $\mathrm{O}$ (b) species determined by high resolution XPS for GNP, $\mathrm{NH}_{2}-\mathrm{GNP}$ and COOH-GNP samples. The bars marked with stars are significantly different with respect to GNP, and the t-test $p$ value is reported on top; in $b$ ), the $p$ values for the $C-O$ and the $C=O / C(O) O H$ and $C(O) N H$ groups are the same, and therefore are reported only once. The $\pi-\pi^{*}$ component has not been accounted in the determination of the relative amount of the $\mathrm{C}$ species, the groups marked with “a” are only present in the $\mathrm{NH}_{2}$-GNP sample 
amino groups on this surface; the presence of oxygen on $\mathrm{NH}_{2}$ GNP is to be related to the formation of amides as shown in Scheme 1d.

The high resolution $\mathrm{C}$ 1s XPS spectra for all samples (Fig. 2a) show a component at $284.4 \mathrm{eV}$ relative to $\mathrm{C}-\mathrm{C}$ carbon, ${ }^{48}$ one at $\sim 290 \mathrm{eV}$ due to the $\pi-\pi^{*}$ transition relative to aromatic carbon, ${ }^{55}$ and three components generated by groups containing $\mathrm{O}$ (and/or $\mathrm{N}$, in $\mathrm{NH}_{2}-\mathrm{GNP}$ ): $\mathrm{C}-\mathrm{O}$ or $\mathrm{C}-\mathrm{N}$ at $285.5-285.7 \mathrm{eV}$, $\mathrm{C}=\mathrm{O}$ and 286.7-286.9 eV, and carboxylic and amidic bonds at $\sim 288 \mathrm{eV}^{56,57}$. The intensity of the $284.4 \mathrm{eV}$ component is significantly higher in the GNP spectrum than in the spectra of the functionalized samples (Fig. 3a), confirming that the functionalization introduces carboxylates and amino groups. The same conclusion can be reached by analysis of the $\mathrm{O} 1 \mathrm{~s}$ spectra, which can be deconvolved into two components at 531.3-531.5 eV ( $\mathrm{C}=\mathrm{O}, \mathrm{COOH}$ and $\mathrm{CONH})$ and 532.8-533.0 eV $(\mathrm{C}-\mathrm{O})^{56,57}$ (Fig 2b). A larger fraction of $\mathrm{COOH}$ and $\mathrm{CONH}$ groups are measured on the functionalized samples than on GNP (Fig 3b). The $\mathrm{N}$ 1s high resolution spectrum (Fig. 2c) shows only one component centered at $400.1 \mathrm{eV}$ on $\mathrm{COOH}-$ GNP, which can be assigned to azo groups, ${ }^{48}$ introduced during functionalization (Scheme 1c). $\mathrm{NH}_{2}$-GNP shows two components, at $399.2 \mathrm{eV}$ and $400.2 \mathrm{eV}$, which can be assigned to primary amino groups, and amide or azo groups respectively. ${ }^{48,54}$

The Raman spectra of the bare and functionalized GNPs show the so-called D and G peaks, centered at approximately 1350 $\mathrm{cm}^{-1}$ and $1580 \mathrm{~cm}^{-1}$ respectively (Fig. 4). ${ }^{58}$ While the $\mathrm{G}$ peak is characteristic of graphite, graphene multilayers and single layers, the D peak is indicative of the presence of defects in the C $\mathrm{sp}^{2}$ network, including for example point defects and crystalline edges.

The reactions carried out to modify GNP decrease the D:G peak intensity ratio (see Table S1 and Fig S1). The superior value of the $D$ peak intensity as compared to $G$, the broadening of both the $\mathrm{D}$ and $\mathrm{G}$ peaks, and the absence of the D' peak $\left(1620 \mathrm{~cm}^{-1}\right)$ within the broad $\mathrm{G}$ peak are indicative of a mean defect spacing below $\sim 5 \mathrm{~nm} .{ }^{59}$ At such high defect density, increasing disorder reduces the ratio of $D$ to $G$ peak intensity. Both the $D$ and the $G$ peaks are blue shifted in the sequence from pristine GNP to COOH-GNP and $\mathrm{NH}_{2}-$ GNP. This shift can be associated with chemical doping, which was induced by the functionalization. ${ }^{60}$

The 2D peak, also referred to as G', normally observed at $2700 \mathrm{~cm}^{-1}$, cannot be observed on any of our samples. This is in agreement with the fact that the $2 \mathrm{D}$ peak intensity decreases, rather than keep increasing, if the average defect spacing goes below $\sim 5 \mathrm{~nm}^{61}$

\section{Graphene- $\mathrm{TiO}_{2}$ Hybrids}

We used COOH-GNP and $\mathrm{NH}_{2}$-GNP as templates for the hydrothermal synthesis of $\mathrm{TiO}_{2}$ using Ti-TEOA 1:2 complex as precursor for $\mathrm{TiO}_{2}$. The method used was similar to that proposed by Kanie and coworkers, ${ }^{19}$ in which the Ti-TEOA complex is incubated in water at $373 \mathrm{~K}$ for 24 hours, and then at $423 \mathrm{~K}$ for 72 hours, in the presence of shape controllers to modify the morphology of the $\mathrm{TiO}_{2}$ particles. In our case, the functionalized graphene acted as shape controller during $\mathrm{TiO}_{2}$ NP growth (samples "COOH-GNP-TiO 2 " and " $\mathrm{NH}_{2}-\mathrm{GNP}$ $\mathrm{TiO}_{2}$ "). For comparison, we synthesized samples in which the $\mathrm{TiO}_{2}$ nanoparticles were grown in contact with nonfunctionalized GNP (sample "GNP-TiO 2 ").

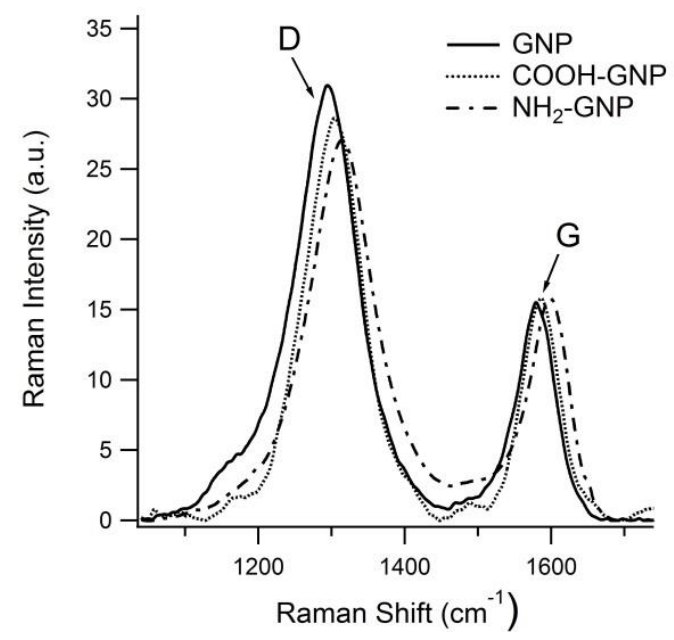

Figure 4: Raman spectra of bare GNP and $\mathrm{COOH}$ and $\mathrm{NH}_{2}$ functionalized GNPs in the $1000-1700 \mathrm{~cm}^{-1}$ range. Spectra are normalized with respect to the $G$ peak, the label $D$ stands for for graphene $D$ peak and $G$ for graphene $G$ peak

We estimated the $\mathrm{Ti}$ content in the resulting composites by comparing the TGA scans obtained on COOH-GNP-TiO ${ }_{2}$ and $\mathrm{NH}_{2}-\mathrm{GNP}_{-} \mathrm{TiO}_{2}$ with that measured on GNP (Fig.5). The weight loss occurring at 500-600 $\mathrm{K}$ on the hybrid samples can be attributed to dehydration. At $973 \mathrm{~K}$, the overall weight loss for the hybrid samples is $4-5 \%$. Considering that the weight loss for GNPs is higher than $85 \%$ at the same temperature, a GNP content below 5-6\% is expected in the hybrid samples.

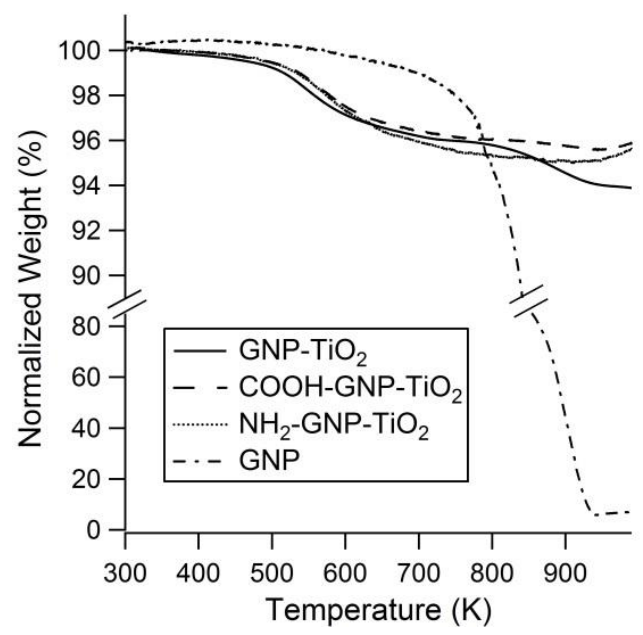

Figure 5: Normalized weight as a function of temperature for $\mathrm{GNP}^{-\mathrm{TiO}}{ }_{2}, \mathrm{COOH}-$ GNP- $\mathrm{TiO}_{2}, \mathrm{NH}_{2}-\mathrm{GNP}-\mathrm{TiO}_{2}$ and GNP. 
Table 2: Carbon, nitrogen, oxygen and titanium content in $\mathrm{GNP}-\mathrm{TiO}_{2}$ hybrids determined by XPS. Uncertainty has been estimated as twice the standard deviation.

\begin{tabular}{|c|c|c|c|c|}
\hline Sample & $\mathrm{C} \%$ at & $\mathrm{O} \%$ at & $\mathrm{N} \%$ at & $\mathrm{Ti} \%$ at \\
\hline $\mathrm{GNP}-\mathrm{TiO}_{2}$ & $24 \pm 1$ & $58 \pm 4$ & $1.0 \pm 0.2$ & $19 \pm 1$ \\
\hline $\begin{array}{c}\mathrm{COOH}-\mathrm{GNP}- \\
\mathrm{TiO}_{2}\end{array}$ & $25 \pm 2$ & $55 \pm 2$ & $0.9 \pm 0.1$ & $19 \pm 1$ \\
\hline $\begin{array}{c}\mathrm{NH}_{2}-\mathrm{GNP}- \\
\mathrm{TiO}_{2}\end{array}$ & $24 \pm 2$ & $56 \pm 2$ & $1.1 \pm 0.6$ & $18 \pm 2$ \\
\hline
\end{tabular}
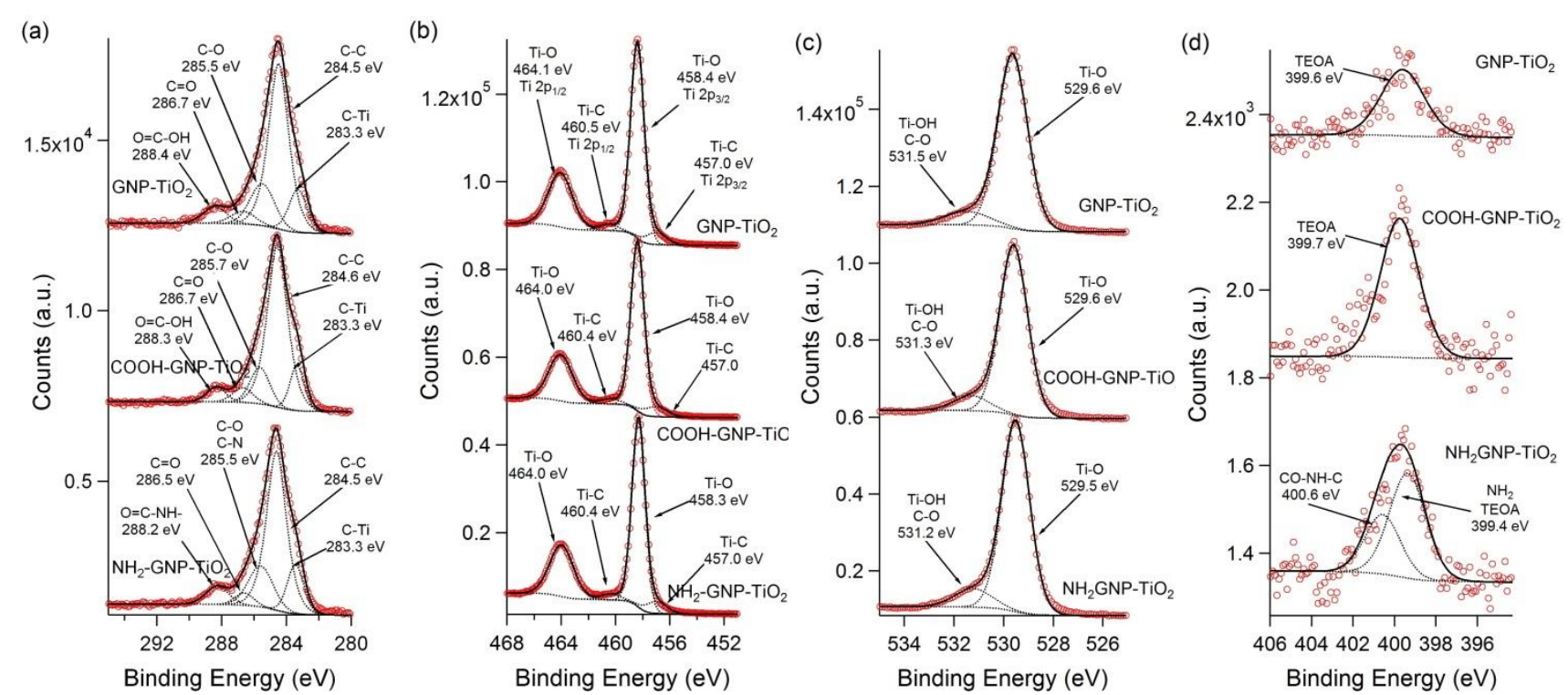

Figure 6: High resolution XPS spectra for $\mathrm{GNP}_{-} \mathrm{TiO}_{2}, \mathrm{NH}_{2}-\mathrm{GNP}-\mathrm{TiO}_{2}$ and $\mathrm{COOH}-\mathrm{GNP}-\mathrm{TiO}_{2}$ samples relative to $\mathrm{C} 1 \mathrm{~s}$ (a), $\mathrm{Ti} 2 \mathrm{p}_{1 / 2}$ and Ti $2 \mathrm{p}_{3 / 2}$ (b), O $1 \mathrm{~s}$ (c), and $\mathrm{N} 1 \mathrm{~s}$ (c)

The $\mathrm{C}, \mathrm{O}, \mathrm{N}$ and Ti atomic \% measured by XPS on the hybrid samples are shown in Table 2.The three hybrid materials have similar $\mathrm{C}, \mathrm{O}, \mathrm{N}$ and $\mathrm{Ti}$ contents, which reflect the similar GNP and $\mathrm{TiO}_{2}$ loadings. The very similar $\mathrm{N}$ content, around $1 \%$, in the three samples is unexpected. TGA indicates that the GNP is diluted approximately 20 times by $\mathrm{TiO}_{2}$. Therefore we would expect only less than $0.5 \% \mathrm{~N}$ in $\mathrm{NH}_{2}-\mathrm{GNP}_{-} \mathrm{TiO}_{2}$ and almost no $\mathrm{N}$ in $\mathrm{COOH}-\mathrm{GNP}-\mathrm{TiO}_{2}$ and $\mathrm{GNP}_{-} \mathrm{TiO}_{2}$. The source of additional nitrogen is most likely residue of the triethanolamine used during the hydrothermal synthesis. XPS (Table 2) shows a lower Ti/C ratio than TGA (Fig. 5), likely due to the fact that XPS probes only the surface, which is often contaminated with excess sources of $\mathrm{C}$, while TGA analyzes the bulk composition. High resolution $\mathrm{C} 1 \mathrm{~s}$ and $\mathrm{Ti} 2 \mathrm{p}$ spectra provide evidence of direct Ti-C bonding (Fig. 6a, b): specifically, the shoulders observed in the $\mathrm{C} 1 \mathrm{~s}$ spectrum at $283.6 \mathrm{eV}$ and at $456.7 \mathrm{eV}$ and $460.4 \mathrm{eV}$ in the $\mathrm{Ti} 2 \mathrm{p}$ spectrum can be assigned to $\mathrm{C}$ - $\mathrm{Ti}$ bonds between GNP and coordinatively unsaturated $\mathrm{Ti}$ atoms. ${ }^{62-65}$ Indeed, even if $\mathrm{TiC}$ is usually characterized by a peak at $281 \mathrm{eV}$ on the $\mathrm{C} 1 \mathrm{~s}$ spectrum $^{63,64}$ and at $454.9-455.1 \mathrm{eV}^{65}$ in the Ti $2 \mathrm{p}_{3 / 2}$ component, higher binding energies similar to that observed in our spectra have been found when the local Ti and $\mathrm{C}$ environments differ from that of bulk TiC. ${ }^{66}$ This is the case for our $\mathrm{GNP}_{-} \mathrm{TiO}_{2}$ hybrids, in which $\mathrm{Ti}$ is mainly present as $\mathrm{Ti}(\mathrm{IV}) \mathrm{O}_{2}$, as revealed by the most intense peaks in the high resolution $\mathrm{Ti}$ and $\mathrm{O}$ spectra corresponding to $\mathrm{Ti}(\mathrm{IV})-\mathrm{O}$ bonds
(BE of $458.4 \mathrm{eV}$ for $\mathrm{Ti} 2 \mathrm{p}_{3 / 2}$ and $464.0 \mathrm{eV}$ for $\mathrm{Ti} 2 \mathrm{p}_{1 / 2}, 529.6$ $\mathrm{eV}$ for $\mathrm{O} 1 \mathrm{~s}$, Fig 5b, c). ${ }^{67}$ The presence of Ti-C bonds on the $\mathrm{GNP}_{-} \mathrm{TiO}_{2}$ hybrids proves that $\mathrm{TiO}_{2}$ nucleation is heterogeneous and occurs on GNP. The relative amount of Ti-C bonds compared to all $\mathrm{C}$ or all $\mathrm{Ti}$ species found on $\mathrm{GNP}_{-} \mathrm{TiO}_{2}$ and on the functionalized $\mathrm{GNP}^{-\mathrm{TiO}_{2}}$ samples are not statistically significantly different (Fig S2).

The other components observed in the $\mathrm{C}$ spectra (Fig. 6a) are similar to what has already been described for the bare and functionalized GNP (Fig. 2).

The peak at $399.3-399.6 \mathrm{eV}$ in the $\mathrm{N} 1 \mathrm{~s}$ spectrum is to be ascribed to triethanolamine for $\mathrm{GNP}_{-} \mathrm{TiO}_{2}$ and $\mathrm{COOH}-\mathrm{GNP}$ $\mathrm{TiO}_{2}$, while it could be related to both triethanolamine and primary amines in $\mathrm{NH}_{2}-\mathrm{GNP}_{-} \mathrm{TiO}_{2}$ (Fig. d). ${ }^{48}$ On this sample, another peak at $400.6 \mathrm{eV}$ is detected and assigned to the amidic functional groups. ${ }^{54}$

The Raman spectra of the composite samples show peaks related to both GNP ( $\mathrm{G}$ and $\mathrm{D}$ peaks in the $1000-1700 \mathrm{~cm}^{-1}$ region) and to $\mathrm{TiO}_{2}$ (in the $100-700 \mathrm{~cm}^{-1}$ region), thus clearly confirming the presence of both components in these materials (Fig. 7).

The D:G peak intensity ratio is significantly lower in the GNP$\mathrm{TiO}_{2}$ hybrids with respect to the corresponding GNP (see Table s1 and Fig. S1). This confirms that the bare and functionalized GNP samples have a high density of defects with mean spacing less than $5 \mathrm{~nm}$. The formation of C-Ti bonds upon nucleation of 
$\mathrm{TiO}_{2}$ on GNP causes a further decrease in the D:G peak intensity ratio. ${ }^{59}$

The peaks related to $\mathrm{TiO}_{2}$ can be used to identify the $\mathrm{TiO}_{2}$ phase (Fig. 7): the five peaks at 144, 197, 399, 516 and $639 \mathrm{~cm}^{-}$ 1 clearly show the formation of anatase on both COOH-GNP$\mathrm{TiO}_{2}$ and $\mathrm{NH}_{2}-\mathrm{COOH}-\mathrm{TiO}_{2} \cdot{ }^{68}$ No other peaks were observed at any of the spots analyzed on these samples (Fig. 7, spectra a and $b$ ). Vice versa, while some spots on $\mathrm{GNP}_{-} \mathrm{TiO}_{2}$ showed only anatase (Fig. 7, spectrum c), others indicated the presence of rutile as well, as evidenced by the appearance of a peak at $440 \mathrm{~cm}^{-1}$ and a shoulder at $600 \mathrm{~cm}^{-1}$ (Fig. 7, spectrum d ). ${ }^{69,70}$ The quantity of rutile in the $\mathrm{GNP}_{-} \mathrm{TiO}_{2}$ sample is, however, too low to be detected by XRD. Indeed, XRD spectra showed the presence of anatase only in all of the $\mathrm{GNP}^{-\mathrm{TiO}_{2}}$ hybrids (Fig. $8) .^{71,72}$

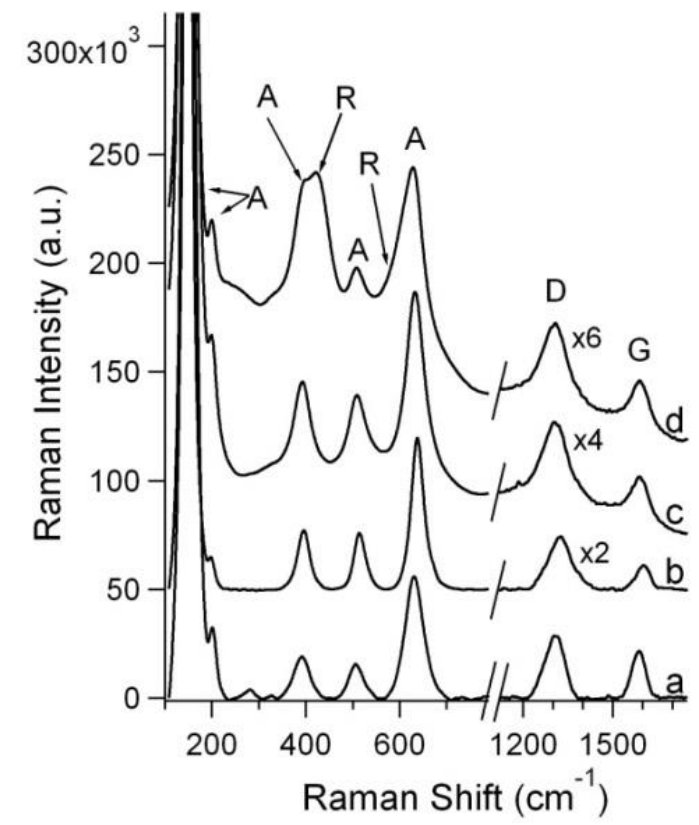

Figure 7: Raman spectra of $\mathrm{COOH}-\mathrm{GNP}-\mathrm{TiO}_{2}(\mathrm{a}), \mathrm{NH}_{2}-\mathrm{GNP}-\mathrm{TiO}_{2}$ (b) and of bare GNP-TiO ${ }_{2}$ sample taken in different spots $(c, d)$. The label A stands for anatase, $R$ for rutile, $D$ for graphene $D$ peak and $G$ for graphene $G$ peak

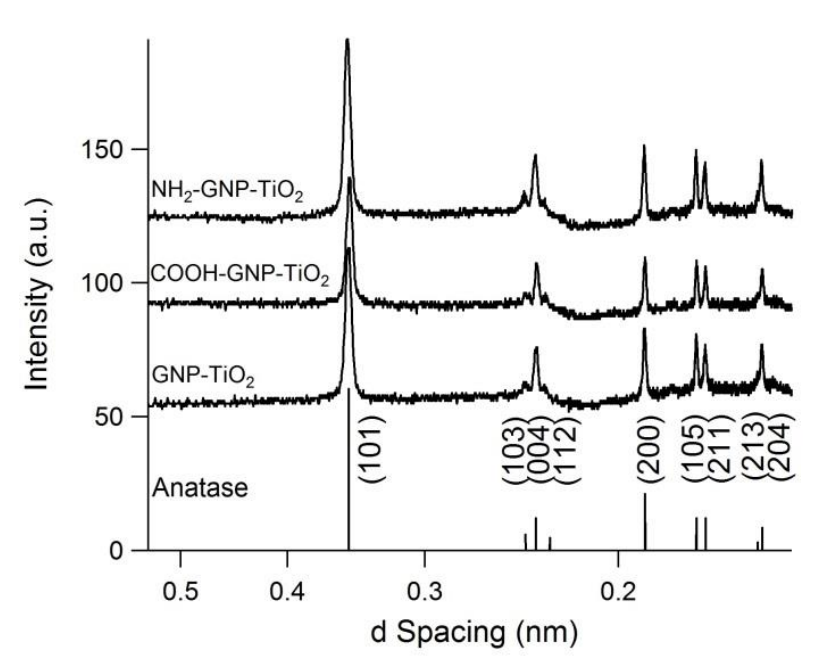

Figure 8: X-ray diffractograms of the $\mathrm{GNP}-\mathrm{TiO}_{2}$ hybrids and the reference pattern for anatase (JCPDS No.21.1272)

\section{GNP-TiO 2 Morphology}

TEM images of the hybrid samples are shown in Figs. 9-11. The low magnification images show well dispersed particles decorating the GNP flakes (Figs. 9a, 10a and 11a); however, on the non functionalized $\mathrm{GNP}^{-\mathrm{TiO}_{2}}$ sample, we observed also a significant amount of $\mathrm{TiO}_{2}$-NPs not bound to the GNP arising from homogeneous nucleation (Fig. S3).

The particles found on COOH-GNP-TiO ${ }_{2}$ are in the shape of truncated bipyramids approximately 30-60 nm long (Fig. 9b and S4). The HR-TEM evidences a line spacing of $0.34 \mathrm{~nm}$ in the exposed trapezoidal facets, identifying them as anatase $\{101\}$ surfaces. $^{20}$ The particles are thus predominantly bound to GNP as shown in the schematic in Fig. 9c.

A representative example of the particles found on $\mathrm{NH}_{2}-\mathrm{GNP}-$ $\mathrm{TiO}_{2}$ is shown in Fig. 10. In this case, the particles are mostly in the shape of belted bipyramids and bipyramids with a higher degree of truncation than what was observed on COOH-GNPTiO2. As shown in Figs. 10c and 10d, these particles are bound with their $\{100\}$ facets on GNP. The presence of belted pyramids implies that more $\{001\}$ and $\{100\}$ surfaces are exposed on this hybrid material than in $\mathrm{COOH}-\mathrm{GNP}_{-} \mathrm{TiO}_{2}$.

The $\mathrm{TiO}_{2}$ particles grown on unfunctionalized GNP are similar in shape and size to the $\mathrm{TiO}_{2}$ NPs formed in solution, ${ }^{19}$ i.e. mostly truncated and belted bipyramids. Such particles were also present on $\mathrm{NH}_{2}-\mathrm{GNP}-\mathrm{TiO}_{2}$; however, the particle edges are less sharp when grown on the unfunctionalized GNP, and the overall appearance is closer to ellipsoidal and spheroidal particles as compared to either of the functionalized GNP composite samples (Fig. 11b). Fig. 11c shows the high magnification micrograph of a belted truncated bipyramid with a high degree of truncation. The $\{100\}$ surface is very developed, while the two trapezoidal $\{101\}$ facets are less extended. The particle is not perfectly symmetric, similar to what was observed for most particles found in this sample 
(Figs. 11a,b). The particles that were homogeneously nucleated in this sample had a similar shape (Fig. S3).

\section{Discussion}

$\mathrm{TiO}_{2}$ shape is normally controlled using molecules in solution. ${ }^{18}$ Here we have shown that the addition of functionalized GNP in the $\mathrm{TiO}_{2}$ precursor solution induces the formation of $\mathrm{TiO}_{2}$ NPs with different morphologies. The resulting $\mathrm{TiO}_{2}$ NPs are bound to the GNP flakes, ${ }^{18,73}$ and the interface between the GNP and the $\mathrm{TiO}_{2}$ in the hybrids can be controlled by the functional groups present on GNP.
Amino functionalization of GNP leads to the formation of truncated bipyramids too, however with sharper edges and less extended $\{100\}$ facets than in the presence of unfunctionalized GNP. Overall, the particles formed with $\mathrm{NH}_{2}$-GNP are similar to those shown in the schematic in Fig. 1b. Such particles are different from particles formed in the presence of aliphatic amines in solution where ellipsoidal particles with extended $\{100\}$ and $\{101\}$ facets were found, with almost negligible $\{001\}$ facets. ${ }^{18}$ This shape was attributed to the adsorption of amines on the $\{100\}$ and $\{101\}$ facets, and their subsequent stabilization at the expenses of the $\{001\}$ facets ${ }^{18}$.
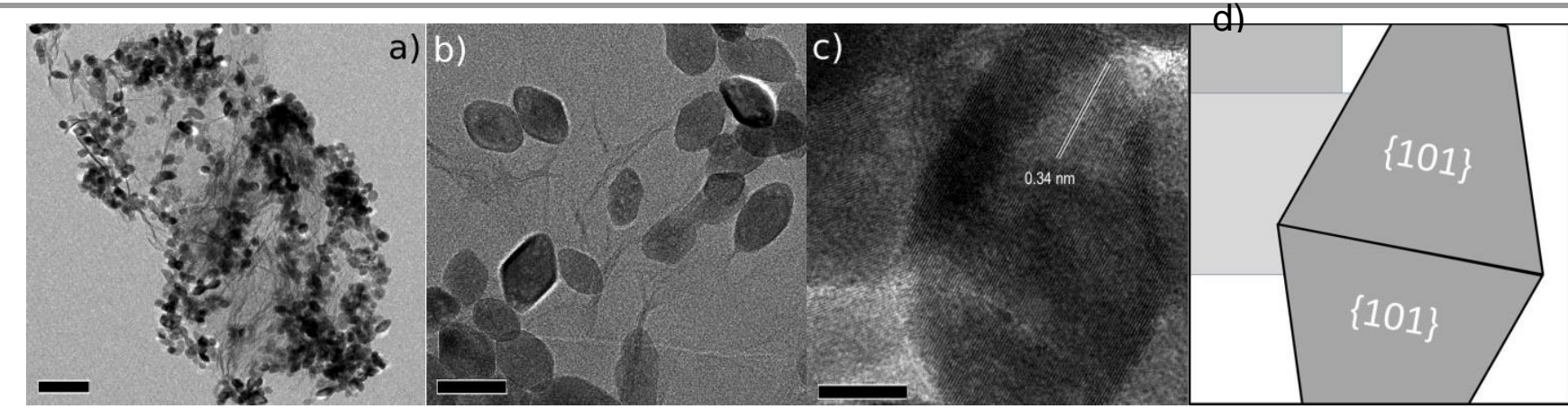

Figure 9: TEM micrographs related to $\mathrm{COOH}-\mathrm{GNP}-\mathrm{TiO}_{2}$ : a) and b) low magnification micrographs, c) high magnification micrograph. The $0.34 \mathrm{~nm}$ spacing shown in c) identifies the two trapezoidal facets as anatase $\{101\}$ facets; d), schematic of c). Scale bars are $200 \mathrm{~nm}$ on a), $50 \mathrm{~nm}$ on b) and $10 \mathrm{~nm}$ on c).

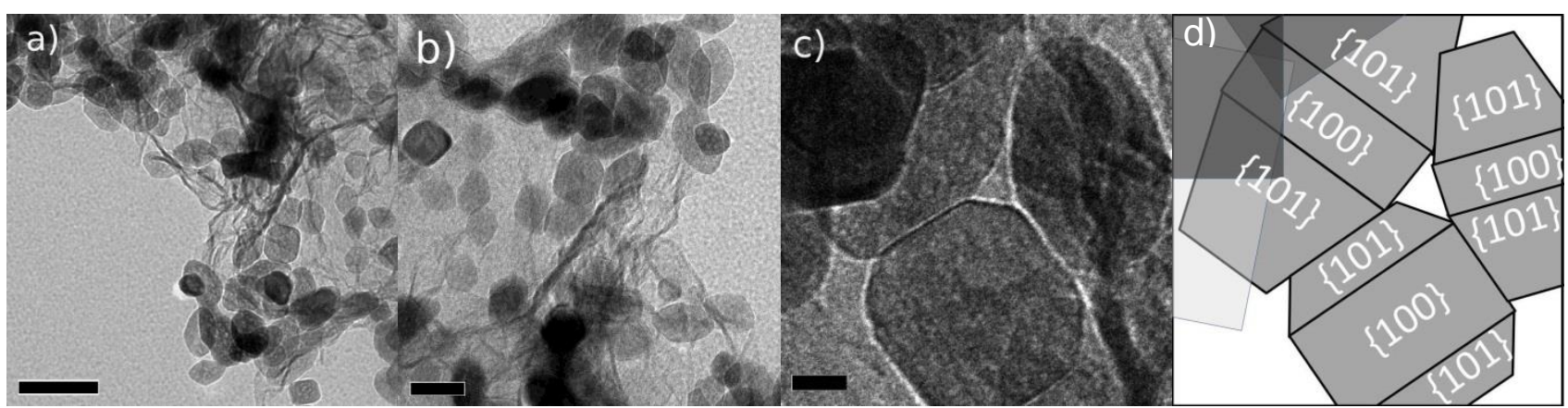

Figure 10: TEM micrographs of $\mathrm{NH}_{2}-\mathrm{GNP}-\mathrm{TiO}_{2}$ sample: a) and b) low magnification, c) high magnification showing belted bipyramid $\mathrm{TiO}_{2}$ nanoparticles. The detectable line spacing is around $0.34 \mathrm{~nm}$ (Fig. S5). These values indicate the presence of the anatase $\{101\}$ and $\{100\}$ surfaces, as shown in d), schematic of c). Scale bars are 200 $\mathrm{nm}$ on a), $50 \mathrm{~nm}$ on b) and $10 \mathrm{~nm}$ on c.
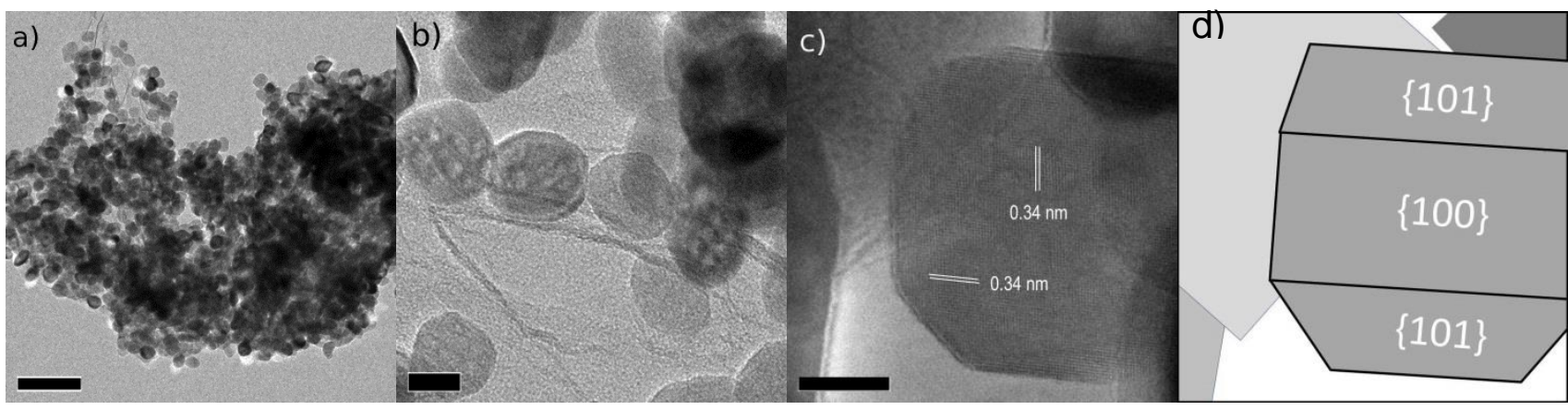

Figure 11: TEM micrographs of $\mathrm{GNP}-\mathrm{TiO}_{2}$ : a) and b) low magnification, c) high resolution showing the $0.34 \mathrm{~nm}$ spacing among crystal planes, indicative of the with anatase $\{101\}$ (trapezoidal) and $\{100\}$ (rectangular) facets, as shown in d). Scale bars are $200 \mathrm{~nm}$ on a), $20 \mathrm{~nm}$ on b) and $10 \mathrm{~nm}$ on c. 
Even more striking differences are observed between the $\mathrm{TiO}_{2}$ particles grown on carboxylated GNP and $\mathrm{TiO}_{2}$ prepared in the presence of carboxylic acids in solution. $\mathrm{COOH}-\mathrm{GNP}_{-} \mathrm{TiO}_{2}$ yields bipyramidal particles with sharp edges and almost no truncation, similar to those shown in the schematic in Fig. 1a. In the presence of oleic and adipic acids, instead, cubic $\mathrm{TiO}_{2}$ nanoparticles are formed, since these molecules strongly adsorb on $\{100\}$ and $\{001\}$ facets and stabilize them at the expenses of the $\{101\}$ facets. ${ }^{18}$

Such differences can be explained by the fact that when the carboxylic groups or the amino groups are immobilized on GNP, they lose mobility and conformational freedom, and thus cannot cap the $\mathrm{TiO}_{2}$ particles and stabilize specific facets. Rather, these groups act as nucleation points for one facet of the particles. Indeed, the bipyramids obtained with $\mathrm{COOH}-$ GNP- $\mathrm{TiO}_{2}$ are similar to those obtained when $\mathrm{TiO}_{2}$ is hydrothermally synthesized without TEOA, at low pH between 0.8 and 1.6. ${ }^{20}$ This similarity suggests that while the bulk pH of the hydrothermal reaction solution is high (between 9.5 and 10), the high surface density of carboxylic acids may generate a local acidic environment in which the $\mathrm{TiO}_{2}$ particles nucleate and grow. In fact, while the truncated bipyramid is the equilibrium shape at low pH (Fig. 1a), the belted bipyramid is the equilibrium shape at basic pH (Fig. 1b). ${ }^{16}$ The latter is the predominant shape found in the presence of $\mathrm{NH}_{2}$-GNP, which favor a local basic environment for $\mathrm{TiO}_{2}$ growth.

In the absence of functional groups, the basic $\mathrm{pH}$ in the bulk of the reaction environment favors the formation of truncated belted pyramids. Such particles are seen on our $\mathrm{GNP}_{-} \mathrm{TiO}_{2}$ hybrids, although with irregular shapes and smooth edges (Fig. 11). This is in agreement with what was observed when $\mathrm{TiO}_{2}$ NPs are prepared in solution without any shape controller. ${ }^{18}$ The absence of functional groups also increases the likelihood of homogenous nucleation (Fig. S3). Homogenously and heterogeneously nucleated particles in the $\mathrm{GNP}_{-} \mathrm{TiO}_{2}$ sample have a similar shape, which further confirms that without functionalization, GNP particles can act as nuclei for $\mathrm{TiO}_{2}$ precipitation but do not influence $\mathrm{TiO}_{2}$ crystal growth.

\section{Conclusions}

We have shown phase and shape control of $\mathrm{TiO}_{2}$ NPs grown on functionalized GNP. The shape control was achieved thanks to changes in local $\mathrm{pH}$ caused by carboxylate and amino functional groups on GNP, where $\mathrm{TiO}_{2}$ nucleation and growth take place. NPs formed on COOH-GNP are bipyramids, which is the equilibrium anatase morphology at acidic $\mathrm{pH}$, and those formed on $\mathrm{NH}_{2}$-GNP are belted bipyramids, the equilibrium anatase morphology at basic $\mathrm{pH}$. Along with shape, we were able to control the facets of the $\mathrm{TiO}_{2}$ NPs bound to GNP, reporting for the first time $\mathrm{TiO}_{2} \mathrm{NPs}$ resting on graphene sheets with facets different from $\{001\}$. This controlled synthesis has the potential to greatly improve the photocatalytic activity of $\mathrm{TiO}_{2}$-GNP hybrids. The binding of $\mathrm{TiO}_{2}\{101\}$ facets to GNP is expected to lead to more efficient transfer of photoelectrons, which in turn should reduce charge recombination and improve photoreduction reaction yield, which is usually the rate limiting process in photocatalysis. ${ }^{74}$ The $\mathrm{GNP}_{-} \mathrm{TiO}_{2}$ hybrids, especially $\mathrm{COOH}-\mathrm{GNP}-\mathrm{TiO}_{2}$, are therefore expected to improve the performance of $\mathrm{TiO}_{2}$ as photocatalysts for water splitting and $\mathrm{H}_{2}$ production.

\section{Acknowledgements}

We acknowledge support from a Marie Curie International Research Staff Exchange Scheme Fellowship (PHOTOMAT, proposal $n^{\circ} 318899$ ) within the $7^{\text {th }}$ European Community Framework Programme, Carvour (Poli Innovazione) PORFESR 07/13, the Canada Research Chair program, the Center for Self Assembled Chemical Structures, the Fonds Quebe cois de la Recherche sur la Nature et les Technologies, and the National Science and Engineering Research Council of Canada. We would like to thank Ms. Isabel Perez for help with the TGA measures.

\section{Notes and references}

\footnotetext{
${ }^{a}$ Materials Engineering, McGill University, 3610 University St., Montreal, QC H3A 0C5, Canada.

${ }^{b}$ Dipartimento di Chimica, Università di Torino, Via P. Giuria, 7, 10125 Torino, Italy.
}

Electronic Supplementary Information (ESI) available: Statistical analysis of the D:G intensity ratio, additional XPS analysis and TEM micrographs. See DOI: 10.1039/b000000x/

\footnotetext{
1. E. Pelizzetti and C. Minero, Comments Inorg. Chem., 1994, 15, 297 - 337.

2. A. Fujishima, T. N. Rao and D. A. Tryk, J. Photochem. Photobiol., C, 2000, 1, 1-21.

B. O'Regan and M. Gratzel, Nature, 1991, 353, 737-740.

A. Fujishima and K. Honda, Nature, 1972, 238, 37-38.

H. Tributsch and B. Neumann, Int. J. Hydrogen Energy, 2007, 32, 2679-2688.

S. U. M. Khan, M. Al-Shahry and W. B. Ingler, Science, 2002, 297, 2243-2245.

M. Zhen, L. Su, Z. Yuan, L. Liu and Z. Zhou, RSC Advances, 2013, 3, 13696-13701.

L. Tan, C. Cao, H. Yang, B. Wang and L. Li, Mater. Lett., 2013, 109, 195-198.

A. G. Dylla, G. Henkelman and K. J. Stevenson, Acc. Chem. Res., 2013, 46, 1104-1112.

U. Diebold, Surf. Sci. Rep., 2003, 48, 53-229.

T. Ohno, K. Sarukawa and M. Matsumura, New J. Chem., 2002, 26, 1167-1170.

T. Taguchi, Y. Saito, K. Sarukawa, T. Ohno and M. Matsumura, New J. Chem., 2003, 27, 1304-1306.

C. Z. Wen, H. B. Jiang, S. Z. Qiao, H. G. Yang and G. Q. Lu, J. Mater. Chem., 2011, 21, 7052-7061.

N. Murakami, Y. Kurihara, T. Tsubota and T. Ohno, J. Phys. Chem. C, 2009, 113, 3062-3069.
} 
T. Tachikawa, N. Wang, S. Yamashita, S.-C. Cui and T. Majima, Angewandte Chemie International Edition, 2010, 49, 8593-8597.

A. S. Barnard and L. A. Curtiss, Nano Lett., 2005, 5, 1261-1266.

G. Wulff, Zeitschrift für Krystallographie und Mineralogie, 1901, 449-530.

T. Sugimoto, X. Zhou and A. Muramatsu, J. Colloid Interface Sci., 2003, 259, 53-61.

K. Kanie and T. Sugimoto, Chem. Commun., 2004, 1584-1585.

Y. Dai, C. M. Cobley, J. Zeng, Y. Sun and Y. Xia, Nano Lett., 2009, 9, 2455-2459.

H. G. Yang, G. Liu, S. Z. Qiao, C. H. Sun, Y. G. Jin, S. C. Smith, J. Zou, H. M. Cheng and G. Q. Lu, J. Am. Chem. Soc., 2009, 131, 40784083.

H. G. Yang, C. H. Sun, S. Z. Qiao, J. Zou, G. Liu, S. C. Smith, H. M. Cheng and G. Q. Lu, Nature, 2008, 453, 638-641.

C.-T. Dinh, T.-D. Nguyen, F. Kleitz and T.-O. Do, ACS Nano, 2009, 3, 3737-3743.

Y. Gao and S. A. Elder, Mater. Lett., 2000, 44, 228-232.

R. L. Penn and J. F. Banfield, Geochim. Cosmochim. Acta, 1999, 63, 1549-1557.

A. Zaban, S. T. Aruna, S. Tirosh, B. A. Gregg and Y. Mastai, J. Phys. Chem. B, 2000, 104, 4130

A. Chemseddine and T. Mortiz, Eur. J. Inorg. Chem., 1999, 235-245.

J. Du, X. Lai, N. Yang, J. Zhai, D. Kisailus, F. Su, D. Wang and L. Jiang, ACS Nano, 2011, 5, 590-596.

M. Long, Y. Qin, C. Chen, X. Guo, B. Tan and W. Cai, J. Phys. Chem. C, 2013, 117, 16734-16741.

L. Sun, Z. Zhao, Y. Zhou and L. Liu, Nanoscale, 2012, 4, 613-620.

J. Liu, H. Bai, Y. Wang, Z. Liu, X. Zhang and D. D. Sun, Adv. Funct. Mater., 2010, 20, 4175-4181.

B. Jiang, C. Tian, W. Zhou, J. Wang, Y. Xie, Q. Pan, Z. Ren, Y. Dong, D. Fu, J. Han and H. Fu, Chem. Eur. J., $2011,17,8379-8387$.

Y.-B. Tang, C.-S. Lee, J. Xu, Z.-T. Liu, Z.-H. Chen, Z. He, Y.-L. Cao, G. Yuan, H. Song, L. Chen, L. Luo, H.-M. Cheng, W.-J. Zhang, I. Bello and S.-T. Lee, ACS Nano, 2010, 4, 3482-3488.

O. Akhavan and E. Ghaderi, J. Phys. Chem. C, 2009, 113, 20214-20220.

G. Williams, B. Seger and P. V. Kamat, ACS Nano, 2008, 2, 1487-1491.

G. Zhu, T. Xu, T. Lv, L. Pan, Q. Zhao and Z. Sun, J. Electroanal. Chem., 2011, 650, 248-251.

S. Sun, L. Gao and Y. Liu, Appl. Phys. Lett., 2010, 96, 083113-083113.

T.-H. Tsai, S.-C. Chiou and S.-M. Chen, Int. J. Electrochem. Sci., 2011, 6, 3333-3343.

C. Chen, W. Cai, M. Long, B. Zhou, Y. Wu, D. Wu and Y. Feng, ACS Nano, 2010, 4, 6425-6432.

J. Zhang, Z. Xiong and X. S. Zhao, J. Mater. Chem., 2011, 21, 3634-3640.

X.-Y. Zhang, H.-P. Li, X.-L. Cui and Y. Lin, J. Mater. Chem., 2010, 20, 2801-2806.

M. S. A. Sher Shah, A. R. Park, K. Zhang, J. H. Park and P. J. Yoo, ACS Appl. Mat. Interfaces, 2012, 4, $3893-3901$.

Y. Wen, H. Ding and Y. Shan, Nanoscale, 2011, 3, 4411-4417.

X. Yang, J. Qin, Y. Li, R. Zhang and H. Tang, J. Hazard. Mater., 2013, 261, 342-350.

Z. He, G. Guai, J. Liu, C. Guo, J. S. Chye Loo, C. M. Li and T. T. Y. Tan, Nanoscale, 2011, 3, 4613-4616.

X. Pan, Y. Zhao, S. Liu, C. L. Korzeniewski, S. Wang and Z. Fan, ACS Appl. Mat. Interfaces, 2012, 4, 3944-3950.

P. Dong, Y. Wang, L. Guo, B. Liu, S. Xin, J. Zhang, Y. Shi, W. Zeng and S. Yin, Nanoscale, 2012, 4, 4641-4649.

G. Zeb, P. Gaskell, X. T. Le, X. Xiao, T. Szkopek and M. Cerruti, Langmuir, 2012, 28, 13042-13050.

C. Peng, Y. Xiong, Z. Liu, F. Zhang, E. Ou, J. Qian, Y. Xiong and W. Xu, Appl. Surf. Sci., 2013, 280, $914-919$.

J. Lyskawa and D. Bélanger, Chem. Mater., 2006, 18, 4755-4763.

D. Belanger and J. Pinson, Chem. Soc. Rev., 2011, 40, 3995-4048.

J. Pinson and F. Podvorica, Chem. Soc. Rev., 2005, 34, 429-439.

S. Mahouche-Chergui, S. Gam-Derouich, C. Mangeney and M. M. Chehimi, Chem. Soc. Rev., 2011, 40, 4143-4166.

S. W. Lee, B.-S. Kim, S. Chen, Y. Shao-Horn and P. T. Hammond, J. Am. Chem. Soc., 2008, 131, 671-679.

J. Matthew, Surf. Interface Anal., 2004, 36, 1647-1647.

D. Yang, A. Velamakanni, G. Bozoklu, S. Park, M. Stoller, R. D. Piner, S. Stankovich, I. Jung, D. A. Field, C. A. Ventrice Jr and R. S. Ruoff, Carbon, 2009, 47, 145-152.

P. S. Johnson, P. L. Cook, X. Liu, W. Yang, Y. Bai, N. L. Abbott and F. J. Himpsel, The Journal of Chemical Physics, 2011, 135, -.

A. C. Ferrari, J. C. Meyer, V. Scardaci, C. Casiraghi, M. Lazzeri, F. Mauri, S. Piscanec, D. Jiang, K. S. Novoselov, S. Roth and A. K. Geim, Phys. Rev. Lett., 2006, 97, 187401

M. M. Lucchese, F. Stavale, E. H. M. Ferreira, C. Vilani, M. V. O. Moutinho, R. B. Capaz, C. A. Achete and A. Jorio, Carbon, 2010, 48, 1592-1597.

M. A. Bissett, M. Tsuji and H. Ago, J. Phys. Chem. C, 2013, 117, 3152-3159.

E. H. Martins Ferreira, M. V. O. Moutinho, F. Stavale, M. M. Lucchese, R. B. Capaz, C. A. Achete and A. Jorio, Phys. Rev. B, 2010, 82, 125429.

B. Liu, Y. Huang, Y. Wen, L. Du, W. Zeng, Y. Shi, F. Zhang, G. Zhu, X. Xu and Y. Wang, J. Mater. Chem., 2012, 22, 7484-7491.

Y.-H. Chang and H.-T. Chiu, J. Mater. Res., 2002, 17, 2779-2782.

J. Luthin and L. Ch, Phys. Scr., 2001, 2001, 134.

J. E. Krzanowski and R. E. Leuchtner, J. Am. Ceram. Soc., 1997, 80, 1277-1280

M. Magnuson, E. Lewin, L. Hultman and U. Jansson, Phys. Rev. B, 2009, 80, 235108

M. C. Biesinger, L. W. M. Lau, A. R. Gerson and R. S. C. Smart, Appl. Surf. Sci., 2010, 257, 887-898.

T. Ohsaka, F. Izumi and Y. Fujiki, J. Raman Spectrosc., 1978, 7, 321-324.

C. A. Chen, Y. S. Huang, W. H. Chung, D. S. Tsai and K. K. Tiong, J. Mater. Sci.: Mater. Electron., 2009, 20, $303-306$.

S. P. S. Porto, P. A. Fleury and T. C. Damen, Physical Review, 1967, 154, 522-526.

C. J. Howard, T. M. Sabine and F. Dickson, Acta Crystallographica Section B, 1991, 47, 462-468.

D. T. Cromer and K. Herrington, J. Am. Chem. Soc., 1955, 77, 4708-4709.

K. S. Kim and M. A. Barteau, Langmuir, 1988, 4, 945-953.

C. Minero, Catal. Today, 1999, 54, 205-216. 